\title{
Editorial
}

\section{El plan nacional de desarrollo 2018-2022: "Pacto por Colombia, pacto por la equidad"}

DOI: https://doi.org/10.19053/01203053.v38.n68.2019.9924

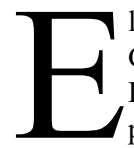

1 presidente de la República, Iván Duque Márquez, sancionó el plan de desarrollo "Pacto por Colombia, pacto por la equidad", establecido por medio de la Ley 1955 del 25 de mayo de 2019. Dicho plan, que se ejecutará en el cuatrienio 2018-2022, se convierte en la hoja de ruta de la política pública y las inversiones durante su período presidencial.

El objetivo central del plan de desarrollo de la actual administración es "sentar las bases de legalidad, emprendimiento y equidad que permita lograr la igualdad de oportunidades para todos los colombianos". El plan consta de 336 artículos e inversiones por 1096,1 billones de pesos de 2018. Esta inversión será financiada en un $66.5 \%$ con recursos del presupuesto nacional, entidades territoriales, regalías, entre otras fuentes gubernamentales; en un $33.1 \%$, por el sector privado, y en el $0.4 \%$, por la cooperación internacional. Entre sus propósitos fundamentales está combatir la pobreza, ya que contempla sacar de la pobreza extrema a 1.5 millones de personas, a 2.9 millones de la pobreza por bajos ingresos y a 2.5 millones de personas de la pobreza multidimensional. De igual manera, se prevé generar 1,6 millones de empleos; ampliar al doble el número de estudiantes, tanto de primaria como de bachillerato en la modalidad de jornada única; reducir las tasas de homicidios; disminuir los cultivos de coca; incrementar la oferta de energía a partir de fuentes limpias, entre otras finalidades. Como puede observarse, son metas bastante loables; no obstante, lo importante será constatar si, efectivamente, en el cuatrienio del mandato del presidente Duque se pueden alcanzar o se quedarán en meras promesas.

Como todo plan nacional de desarrollo, el actual no ha estado exento de críticas. Uno de los cuestionamientos más fuertes es que, tal y como lo estableció la Constitución de 1991, se esperaba que la propuesta presentada al Congreso fuera analizada y debatida en profundidad, tanto por la Cámara de Representantes como por el Senado. Si bien en la Cámara se discutió ampliamente, lo que llevó a que muchas de las propuestas iniciales fueran descartadas y otras cambiadas o modificadas, en el Senado no hubo tiempo para ello y su aprobación fue rápida, por lo cual acogió, básicamente, el proyecto aprobado en la Cámara.

En general, el plan propone una serie de reformas en varios temas y, por ello, algunos analistas como Guillermo Perry, Salomón Kalmanovitz, Eduardo Sarmiento, entre otros, cuestionan que en vez de enfocarse exclusivamente en reformas prioritarias para llevar a cabo el programa de Gobierno del presidente Duque, incursionó en temas laborales, tributarios, de comercio exterior, pensionales, etc., los cuales deben ser objeto de otras disposiciones.

En lo laboral, en el artículo 193 se afirma: "Las personas que tengan relación contractual laboral o por prestación de servicios, por tiempo parcial y que en virtud de ello perciban un ingreso mensual inferior a un (1) salario mínimo mensual legal vigente - SMLMV deberán vincularse al piso de protección social [...]”. Con esta iniciativa, el Gobierno se propone legalizar la contratación laboral por horas o por debajo de un salario mínimo, lo cual va en detrimento de los trabajadores, pues desconoce los avances obtenidos en las negociaciones colectivas y representa una agresión al salario mínimo, tal como lo ha planteado la Central Unitaria de Trabajadores (CUT). 
En materia tributaria se presenta una serie de proposiciones, siendo lo más cuestionable lo estipulado en el artículo 313, relacionado con Electricaribe, y que rige desde que se firmó la ley hasta el 31 de diciembre de 2022. En dicho artículo se crea una sobretasa nacional de cuatro pesos por kilovatio hora de energía eléctrica consumido, para rescatar financieramente a Electricaribe, la cual deberá ser pagada por "los estratos 4, 5 y 6 , los usuarios comerciales e industriales y los no regulados del servicio de energía eléctrica", de todo el país. En otras palabras, por culpa del despilfarro, la corrupción y la mala administración de Electricaribe, tendrá que responder un grupo considerable de la población.

En lo referente al comercio exterior, se aprobó un aumento de aranceles a las importaciones de textiles, el cual quedó en $37.9 \%$ y regirá a partir de la firma de la ley del plan. Este incremento, según la Asociación Nacional de Empresarios de Colombia (ANDI), representa un aumento del $25 \%$ en el precio de los productos importados, que tendrá que cubrirlo el consumidor. Esta decisión ha sido cuestionada por los gremios de la producción (ANDI, ANALDEX y FENALCO), en la medida que se considera que el Congreso se extralimitó, ya que estos impuestos deben crearse por vía administrativa y no legislativa; por consiguiente, estos gremios lo demandarán por considerarlo inconstitucional.

En lo pensional, en el artículo 198 se plantea que si una persona no llena los requisitos para recibir una pensión, los aportes económicos que haya realizado en su vida laboral serán trasladados al mecanismo de los Beneficios Económicos Periódicos (BEPS), que le garantizarán el acceso a una renta vitalicia. Sin embargo, en el mencionado artículo también se establece que el afiliado tendrá derecho a solicitar la devolución de sus ahorros dentro de los seis (6) meses siguientes de haber sido informado de la posibilidad del traspaso de los mismos a los BEPS.

En general, en el plan nacional de desarrollo "Pacto por Colombia, pacto por la equidad", se propone un conjunto de reformas en los más diversos campos, por lo que cabe preguntarse - asunto que revisará la Corte Constitucional-, si se cumplieron principios como unidad de materia o si, más bien, es una "colcha de retazos", donde tanto el Ejecutivo como el Legislativo introdujeron una serie de propuestas que, aunque importantes, no debían incluirse, por ser de competencia de otras entidades, situación que plantea serias dudas sobre la legalidad y legitimidad de dichas propuestas.

Además, en la ley del plan se afirma que el plan nacional del desarrollo se basa en tres pactos estructurales: legalidad, emprendimiento y equidad. En el primero, la idea básica es la lucha contra la corrupción, por lo que es oportuno preguntarse hasta qué punto tanto el presidente como su partido político están verdaderamente comprometidos con el combate contra dicho flagelo, ya que, en buena parte, el hundimiento del proyecto anticorrupción en el Congreso se debió a que dicho proyecto no fue de su interés. Cabe recordar que, si bien, inicialmente, el Ejecutivo declaró que el proyecto anticorrupción tendría mensaje de urgencia, en la práctica terminó relegado por darle mayor atención a otras iniciativas legislativas. Y, en cuanto a la equidad, hay que resaltar la dificultad de alcanzarla, pues el plan contiene varios artículos de fuerte impacto tributario que benefician sustancialmente a los dueños del capital y que, sin lugar a dudas, afectarán los ingresos de las personas más vulnerables.

Luis Eudoro Vallejo Zamudio Director de la Revista Apuntes del Cenes 